\title{
Resilience, Emotions, and Character Strengths as Predictors of Job Stress in Military Personnel
}

\author{
Arsia Taghva ${ }^{1}$, Seyed Teymur Seyedi Asl ${ }^{2,}{ }^{*}$, Amir Mohsen Rahnejat ${ }^{2}$ and Mohammad Mehdi Elikaee ${ }^{3}$ \\ ${ }^{1}$ Psychiatry Department, Faculty of Medicine, Aja University of Medical Sciences, Tehran, Iran \\ ${ }^{2}$ Clinical Psychology Department, Medical Faculty, Aja University of Medical Sciences, Tehran, Iran \\ ${ }^{3}$ Medical Faculty, Aja University of Medical Sciences, Tehran, Iran \\ "Corresponding author: Clinical Psychology Department, Faculty of Medicine, Aja University of Medical Sciences, Tehran, Iran. Tel/Fax: +98-2166125686, Email: \\ teymur.psychology@gmail.com
}

Received 2018 November 24; Revised 2020 April 12; Accepted 2020 May 10.

\begin{abstract}
Background: Job stress, which undermines productivity and physical and mental health, has been reported to be high among military personnel.

Objectives: The present study aimed to explore the role of character strengths, emotions, and resilience in predicting job stress in a sample of Iranian military personnel.

Methods: This cross-sectional study recruited a total number of 146 military personnel via convenience sampling and administered the Health and Safety Executive Stress Questionnaire, Conner-Davidson Resilience Scale, Values in Action Inventory of Strengths, and Positive and Negative Affect Schedule. The correlation analysis and stepwise linear regression were performed using SPSS22.

Results: Job stress was negatively associated with resilience, positive emotions, and character strengths and positively associated with negative emotions $(\mathrm{P}<0.001)$. Regression analysis revealed that three variables, including resilience, courage, and negative emotions could predict $57 \%$ of the variance in job stress (Adj. $\mathrm{R}^{2}=0.57, \mathrm{P}<0.001$ ).

Conclusions: Higher resilience and courage are associated with lower job stress. Also, negative emotions such as anger, guilt, and anxiety would contribute to higher job stress. Providing training courses to develop and boost resilience and courage and manage negative emotions can offset the negative effects of job stress on military personnel. Also, considering these factors as recruitment criteria would lead to the enlistment of cadets who may be more resilient to stress.
\end{abstract}

Keywords: Character Strengths and Virtues, Emotions, Military Personnel, Resilience, Job Stress

\section{Background}

Major corporations and sensitive positions, such as the military, often require their staff to have or show superior physical and psychological qualities. For this reason, work-related stress is considered a major factor threatening mental health (1). In the military, in particular, personnel are bound by strict discipline and absolute obedience and may be exposed to greater extents of stress in their work environment compared to workers in other occupations (2). Military personnel has been reported to experience high levels of job stress compared to people in occupations, such as nursing (3).

Job/work stress refers to anxiety, tension, or stress related to one's job (4). Indeed, a person is said to have job stress when he is beset by feelings of toughness, tension, anxiety, frustration, distress, and worry regarding his job (5). Owing to an abundance of unexpected and potential hazards, which contribute greatly to job stress, military personnel tend to experience higher levels of job stress compared with other people (6). Also, because of the nature of the military career, which necessitates keeping a perpetual state of physical and mental readiness, a military setting is conducive to mental stress. Continuous stress would have significant implications for the family, as well as the workplace environment, including showing disciplinary, authoritarian, and harsh behaviors at home (7).

Several studies have shown that military personnel has high levels of job stress. Azad Marzabadi and Niknafs studied 595 military personnel from various departments in Iran and reported a high level of job stress in the study sample compared to the regular population (7). Pflanz and Ogle, in their study of 809 military personnel, found that $27 \%$ of them suffered from high job stress (8). Another study with 87 active-duty military personnel reported the presence of work-related stress in more than $60 \%$ of the 
personnel (9). Other studies have also reported high levels of job stress in military personnel $(10,11)$. Given the high levels of job stress in military personnel, identifying factors and personality traits contributing to this issue can have significant implications for the management of job stress among military personnel.

Resilience has been the subject of extensive research in military settings. Various definitions have been proposed for resilience, including coping with stress and adversities and tragic events that contribute to the development and enrichment of protective factors (12). Resilience has been defined as a capacity stemming from self-esteem, emotional stability, or personality characteristics that help a person overcome difficulties, survive stress, and stand up to disadvantages (13). Bonanno defines resilience as the individuals' ability to maintain psychological stability in the face of potentially disruptive events such as the death of a close relation, violence, or life-threatening situations (14). Various studies on military personnel have shown that psychological resilience significantly contributes to recovery from depression $(15,16)$, posttraumatic stress disorder $(15$, 17, 18), impaired mental health (19), and alcohol misuse (20).

The association of resilience with job stress in military personnel has been examined in several studies. In a study of 2,063 employees in demanding professions, including the military, Shatté et al. found resilience as an important predicting factor for job stress (21). Rees et al. reported a strong correlation between resilience and workplace stress (22). On the other hand, recent research suggests that positive psychological variables such as character strengths and positive or negative emotions may also predict job stress in military personnel.

Positive psychology was introduced by Seligman and Csikszentmihalyi in 2000. It was a response to the illnesscentric approach that had dominated psychology since World War II (23). Positive psychology holds that the mere treatment of disease symptoms is not sufficient and that the lives of people should be guided in a positive direction to thrive $(24,25)$. The other objective of this approach is to try to ameliorate the problems and disorders by concentrating on positive aspects of life, individuals' capabilities, and positive emotions rather than focusing on the negatives of the individual's life and personality (26). Character strengths and virtues and positive emotions are two positive psychology variables that have been investigated for their potential role in the prevention of psychological problems. In their book "Character Strengths and Virtues", Peterson and Seligman attempt to classify the humanistic ideals of virtues. Their goal is to develop a positive psychology version of the Diagnostic and Statistical Manual of Mental Disorders by providing a classification sys- tem for human abilities. They finally came up with six virtues known to be common to all religions and creeds: wisdom, courage, humanity, justice, temperance, and transcendence (27). Studies have also been performed on the predictive role of positive emotions $(26,28)$. Some studies have pointed to the association of resilience with character strengths (29) and emotions (30). Since resilience is considered a predictor of job stress, it is possible that character strengths and emotions may also predict job stress.

The findings from different studies show that some of the positive psychology variables such as character strengths and positive emotions can influence various aspects of the individuals' functioning. However, since positive psychology is a relatively novel approach, the number of studies is limited. To the best of our knowledge, no study has taken into account all of the aforementioned variables to relate the positive psychology approach to the findings of the other fields of psychology.

\section{Objectives}

The present study aimed to examine character strengths, emotions, and resilience as predictors of job stress in military personnel in Iran.

\section{Methods}

\subsection{Sample and Procedure}

In the present cross-sectional study conducted in 2017 $-18,146$ military personnel were recruited through convenience sampling. The inclusion criteria were (a) being a permanent employee of the Iranian military, (b) holding a sergeant rank or higher, and (c) being 20 to 65-years-old. The exclusion criterion was having a mental illness, according to self-declaration. The procedure of data collection was as follows: First, questionnaires were distributed to the military personnel who were willing to fill in them. For this purpose, various military centers were visited in Tehran. In the second phase, two weeks later, researchers again visited the same military centers and received complete questionnaires. Finally, the collected questionnaires were coded, and the data were entered into statistical software.

\subsection{Research Tools}

\subsubsection{Health and Safety Executive Stress Questionnaire (HSE)}

The questionnaire was developed by the UK Health and Safety Executive in the late 1990s to assess workplace stress in workers and employees in the UK (31). It has 35 items 
making up seven components, including demand, role, relationship, support from management, support from colleagues, control, and change (32). The reliability and validity of the HSE questionnaire have been assessed in several studies. MacKay et al. reported Cronbach's alpha for the questionnaire and its components to range from 0.63 to 0.83 (33). Kerr et al. reported a Cronbach's alpha coefficient of 0.83 and good construct validity (34). Marzabadi and Gholami Fesharaki (32) found a negative correlation between HSE and the General Health Questionnaire ( $\mathrm{r}=$ 0.48). They reported the validity and split-half reliability of the questionnaire to be 0.78 and 0.65 , respectively. They also demonstrated strong correlations among the factors extracted from the items of the HSE (role: 0.92; relationship: 0.73; support from management: 0.75; support from colleagues: 0.63 ; control: 0.87 ; demand: 0.85 ; and change: 0.22 ).

\subsubsection{Connor-Davidson Resilience Scale (CD-RIS)}

The scale was developed by Connor and Davidson as a means of assessing resilience (35). It contains 25 items rated on a 5-point Likert scale from 0 (not true at all) to 4 (true at all times). The total score ranges from 0 to 100 , with higher scores corresponding to higher resilience. The psychometric properties of the scale were evaluated in various populations, including a community sample, primary care outpatients, general psychiatric outpatients, a clinical trial of generalized anxiety disorder, and two clinical trials of PTSD. The developers of the instrument concluded that the scale could discriminate resilient individuals in both clinical and non-clinical populations (35). The Persian version of this questionnaire has a Cronbach's alpha of 0.73 to $0.91(36,37)$.

\subsubsection{Values in Action Inventory of Strengths (VIA-IS)}

This inventory was developed by Seligman and Peterson in 2003 as a means of evaluating 24 character strengths composing of six virtues. The short form of the questionnaire contains 48 items, and both the internal consistency and test-retest reliability of the questionnaire were $>0.7$ (28). In a study in Iran, Cronbach's alpha of 0.98 was obtained (38).

\subsubsection{Positive and Negative Affect Schedule (PANAS)}

This is a self-report questionnaire widely used to measure positive and negative emotions. It was developed by Watson and colleagues in 1988 and is composed of two 10item scales for assessing both positive and negative affect. They reported alpha coefficients for positive and negative affect to be 0.88 and 0.87 , respectively. Also, the questionnaire has eight-week retest reliability of 0.68 for positive affect and 0.71 for negative affect (39). Khodarahimi reported a high internal consistency of 0.90 in an Iranian sample (40).

Also, a questionnaire was used to collect the demographic characteristics of the participants, including age, gender, marital status, and years of service.

\subsection{Date Analysis}

Data were analyzed using SPSS22. The data are presented as mean \pm standard deviation or frequencies, as appropriate. Pearson correlation coefficients were calculated to analyze the strength of associations between job stress and each of the variables. Stepwise linear regression was used to evaluate how well resilience, emotions, and character strengths predicted job stress in participants.

\section{Results}

A total of 146 military personnel participated in the study. The mean age and years of service were $28.07 \pm 8.48$ and $11.92 \pm 7.1$ years, respectively. The sample was composed of 142 male (97\%) and 4 (3\%) female personnel. Singles made up about $64 \%(n=94)$ of the sample. Of the married participants, three (2\%) had no children, 24 (17\%) had one child, 18 (12\%) had two children, and seven (5\%) had three children. Table 1 presents the results of the correlation analyses.

Job stress was negatively correlated with resilience, positive emotions, and all the components of character strengths, and the correlations were significant $(\mathrm{P}<0.01)$. However, the association between job stress and negative emotions was significantly positive $(\mathrm{P}<0.01)$.

Table 2 shows the results of stepwise regression analysis. In the first step of regression analysis, resilience was entered in the regression equation, and it could predict $50 \%$ of the variance in job stress (Adj. $\mathrm{R}^{2}=0.50, \mathrm{P}<0.001$ ). In the second step, courage was entered in the equation and, together with resilience, predicted $55 \%$ of the variance in job stress (Adj. $\mathrm{R}^{2}=0.55, \mathrm{P}<0.001$ ). Finally, the negative emotions variable was entered in the equation, and the three variables could predict $57 \%$ of the variance in job stress (Adj. $\mathrm{R}^{2}=0.57, \mathrm{P}<0.001$ ).

\section{Discussion}

Our results showed that resilience, courage (a character virtue), and negative emotions could predict job stress. Therefore, job stress decreased as resilience and courage increased and negative emotions decreased, and vice versa.

Our findings are consistent with the findings of previous studies on the association of job stress with resilience 


\begin{tabular}{|c|c|c|c|c|c|c|c|c|c|c|c|c|c|}
\hline Variables & Subscales & $\mathbf{M}$ & SD & 1 & 2 & 3 & 4 & 5 & 6 & 7 & 8 & 9 & 10 \\
\hline Job stress & Job stress & 96.85 & 15.53 & 1 & & & & & & & & & \\
\hline Resilience & Resilience & 62.45 & 14.02 & $-0.66^{\mathrm{a}}$ & 1 & & & & & & & & \\
\hline \multirow{2}{*}{ Emotions } & Positive emotions & 34.97 & 6.75 & $-0.41^{\mathrm{a}}$ & $0 / 35^{\mathrm{a}}$ & 1 & & & & & & & \\
\hline & Negative emotions & 19.38 & 6.11 & $0.42^{\mathrm{a}}$ & $-0.32^{\mathrm{a}}$ & $-0.41^{\mathrm{a}}$ & 1 & & & & & & \\
\hline \multirow{6}{*}{ Character strengths } & Wisdom & 25.77 & 4.42 & $-0.47^{\mathrm{a}}$ & $0.51^{\mathrm{a}}$ & 0.07 & -0.01 & 1 & & & & & \\
\hline & Courage & 25.67 & 4.17 & $-0.58^{\mathrm{a}}$ & $0.59^{\mathrm{a}}$ & 0.128 & -0.07 & $0.62^{\mathrm{a}}$ & 1 & & & & \\
\hline & Humanity & 25.40 & 4.45 & $-0.49^{\mathrm{a}}$ & $0.57^{\mathrm{a}}$ & $0.26^{\mathrm{a}}$ & $-0.23^{\mathrm{a}}$ & $0.54^{\mathrm{a}}$ & $0.62^{\mathrm{a}}$ & 1 & & & \\
\hline & Justice & 25.76 & 4.16 & $-0.47^{\mathrm{a}}$ & $0.59^{\mathrm{a}}$ & 0.13 & -0.10 & $0.56^{\mathrm{a}}$ & $0.69^{\mathrm{a}}$ & $0.64^{\mathrm{a}}$ & 1 & & \\
\hline & Temperance & 25.89 & 3.65 & $-0.44^{\mathrm{a}}$ & $0.48^{\mathrm{a}}$ & 0.16 & -0.09 & $0.54^{\mathrm{a}}$ & $0.56^{\mathrm{a}}$ & $0.47^{\mathrm{a}}$ & $0.59^{\mathrm{a}}$ & 1 & \\
\hline & Transcendence & 26.05 & 5.45 & $-0.43^{\mathrm{a}}$ & $0.32^{\mathrm{a}}$ & 0.08 & -0.09 & $0.43^{\mathrm{a}}$ & $0.28^{\mathrm{a}}$ & $0.34^{\mathrm{a}}$ & $0.40^{\mathrm{a}}$ & $0.26^{\mathrm{a}}$ & 1 \\
\hline
\end{tabular}

$$
{ }^{\mathrm{a}} \mathrm{P}<0.01
$$

Table 2. Stepwise Linear Regression Analysis to Predict Job Stress Based on Resilience, Emotions, and Character Strengths

\begin{tabular}{|c|c|c|c|c|c|c|c|c|c|c|c|}
\hline Dependent & Step & Predictors & $\mathbf{R}$ & $\mathbf{R}^{2}$ & Adj. $\mathrm{R}^{2}$ & $\mathbf{F}$ & $\mathbf{P}$ & B & $\beta$ & $\mathbf{T}$ & $\mathbf{P}$ \\
\hline \multirow{6}{*}{ Job stress } & 1 & Resilience & 0.71 & 0.50 & 0.50 & 88.29 & $<0.001$ & -0.83 & -0.71 & -9.39 & $<0.001$ \\
\hline & \multirow{2}{*}{2} & Resilience & \multirow{2}{*}{0.74} & \multirow{2}{*}{0.56} & \multirow{2}{*}{0.55} & \multirow{2}{*}{53.69} & \multirow{2}{*}{$<0.001$} & -0.63 & -0.54 & -5.92 & $<0.001$ \\
\hline & & Courage & & & & & & -1.16 & -0.28 & -3.14 & 0.002 \\
\hline & \multirow{3}{*}{3} & Resilience & \multirow{3}{*}{0.77} & \multirow{3}{*}{0.59} & \multirow{3}{*}{0.57} & \multirow{3}{*}{40.21} & \multirow{3}{*}{$<0.001$} & -0.49 & -0.42 & -4.26 & $<0.001$ \\
\hline & & Courage & & & & & & -1.29 & -0.31 & -3.55 & 0.002 \\
\hline & & $\begin{array}{l}\text { Negative } \\
\text { emotions }\end{array}$ & & & & & & 0.53 & 0.20 & 2.52 & 0.013 \\
\hline
\end{tabular}

$(21,22)$. Also, various studies have documented the significant protective effect of resilience against depression (15, 16), PTSD (15, 17, 18), impaired mental health (19), and alcohol misuse (20) in military personnel. Resilience is a capacity that helps the individual to cope better with stress and difficulties. People with high psychological resilience possess greater abilities to recover from stressful situations (41) and can positively adapt to those situations (42).

Although no study has looked at the association of job stress with emotions and character strengths, the relationship between resilience and character strengths (29) and emotions (30) has been demonstrated, and resilience is related to job stress. According to positive psychology, developing and boosting positive emotions, as well as dealing with negative emotions, can shield us against more severe psychological problems. This approach, therefore, sees emotions as crucial factors affecting mental health (26).

Our finding that the virtue of courage is a predictor of job stress implies that having the courage to overcome and not give in to barriers would help individuals achieve their goals. Courage is defined as believing in what one does in facing difficulties. A person with courage performs confi- dently and is not scared of objection or criticism (43). Such a quality could be useful in a stressful military setting. On the other hand, courage is a highly esteemed virtue in the military, and those who display courage will earn the respect of their compatriots in the long run.

Research indicates that character strengths and virtues are considered key characteristics in the militaries of different countries, and their significance to the organization of the military is increasingly being recognized. Among them, bravery has received more attention. A study, for example, compared two samples of military cadets (from the US and Norway) and a sample of US civilians in terms of character strengths and found that bravery was among the greatest strengths present in the military cadets (44).

\subsection{Conclusion}

On the whole, possessing greater resilience and courage seems to positively affect job stress in military personnel. Also, negative emotions such as anger, guilt, and anxiety are associated with greater job stress. An important implication of the present study is that resilience and courage can be enhanced, and negative emotions may be managed through training courses. These courses 
can indirectly affect job stress. Also, considering these strengths in enlisting recruits will make it possible to select individuals with higher resilience and courage and less negative emotions.

However, owing to some limitations in the study, caution should be exerted in the generalization of the findings. Among the limitations of the study are not distinguishing among different kinds of work stress in different sections of the military and providing inaccurate responses because of the relatively large number of questions. Moreover, the major limitation of the study was related to the sampling method. Convenience sampling leads to bias in findings.

\section{Acknowledgments}

We would like to thank all the military personnel who participated in the study.

\section{Footnotes}

Authors' Contribution: Arsia Taghva and Seyed Teymur Seyedi Asl designed the Study. Mohammad Mehdi Elikaee and Seyed Teymur Seyedi Asl Analyzed and interpreted the data. Arsia Taghva Drafted the manuscript. Seyed Teymur Seyedi Asl and Amir Mohsen Rahnejat Critically revised the manuscript for important intellectual content. All authors read and approved the final manuscript.

Conflict of Interests: We have no conflict of interest to declare.

Ethical Approval: The study was approved by the University Research Council on September 11, 2017, with number IR.AJAUMS.REC.1398.262.

Funding/Support: The present study was funded by the Research Department of AJA University of Medical Sciences.

\section{References}

1. Rajabi Gilan N, Ghasemi S, Amini S, Reshadat S, Zakiei A, Jamshidinazar F. Job Stress in Accordance with Organizational Commitment and Social Capital. Iran J Psychiatry Behav Sci. 2018;12(2). e10382. doi: 10.5812/ijpbs.10382.

2. Refahi SAA, Ebadi A, Hadian Mobarakeh R, Jafari R. [The relationship between burnout and some demographic characteristics and job security in police personnel of Sistan and Baluchestan Province]. Police Manag Stud Q. 2012;8(3):443-457. Persian.

3. Tao N, Zhang J, Song Z, Tang J, Liu J. Relationship between job burnout and neuroendocrine indicators in soldiers in the Xinjiang arid desert: a cross-sectional study. Int JEnviron Res Public Health. 2015;12(12):1515461. doi: 10.3390/ijerph121214977.

4. Lambert EG, Qureshi H, Frank J, Klahm C, Smith B. Job stress, job involvement, job satisfaction, and organizational commitment and their associations with job burnout among Indian police officers: a research note. J Police Crimin Psychol. 2018;33(2):85-99. doi: 10.1007/s11896-017-9236-y.
5. Griffin ML, Hogan NL, Lambert EG, Tucker-Gail KA, Baker DN. Job Involvement, Job Stress, Job Satisfaction, and Organizational Commitment and the Burnout of Correctional Staff. J Crimin Justice Behave. 2010;37(2):239-55. doi:10.1177/0093854809351682.

6. Azad Marzabadi E, Gholami Fesharaki M. [Effective factors on job stress in military personnel].J Mil Med. 2011;13(1):1-6. Persian.

7. Azad Marzabadi E, Niknafs S. [Models of Opposing Against Job Stress among Military Staff]. Payavard Salamat. 2016;10(4):299-310. Persian.

8. Pflanz SE, Ogle AD. Job stress, depression, work performance, and perceptions of supervisors in military personnel. Mil Med. 2006;171(9):861-5. doi:10.7205/milmed.171.9.861. [PubMed: 17036607].

9. Pflanz S. Occupational stress and psychiatric illness in the military: investigation of the relationship between occupational stress and mental illness among military mental health patients. Mil Med. 2001;166(6):457-62. doi: 10.1093/milmed/166.6.457. [PubMed: 11413719].

10. Hourani LL, Williams TV, Kress AM. Stress, mental health, and job performance among active duty military personnel: findings from the 2002 Department of Defense Health-Related Behaviors Survey. Mil Med. 2006;171(9):849-56. doi: 10.7205/milmed.171.9.849. [PubMed: 17036605].

11. Pflanz S, Sonnek S. Work stress in the military: prevalence, causes, and relationship to emotional health. Mil Med. 2002;167(11):877-82. [PubMed: 12448610].

12. Richardson JW. From risk to resilience: Promoting school-health partnerships for children. Int J Edu Reform. 2008;17(1):19-36. doi: $10.1177 / 105678790801700103$.

13. Moghimi M, Esmaeilpour N, Karimi Z, Zoladl M, Moghimi MA. Effectiveness of Resilience Teaching via Short Message Service on Stress of Mothers of Educable Mentally Retarded Children. Iran J Psychiatry Behav Sci. 2018;In Press(In Press). e59966. doi: 10.5812/ijpbs.59966.

14. Bonanno GA. Loss, trauma, and human resilience: have we underestimated the human capacity to thrive after extremely aversive events? Am Psychol. 2004;59(1):20. doi: 10.1037/0003-066x.59.1.20. [PubMed: 14736317].

15. Vyas KJ, Fesperman SF, Nebeker BJ, Gerard SK, Boyd ND, Delaney EM, et al. Preventing PTSD and depression and reducing health care costs in the military: a call for building resilience among service members. Mil Med. 2016;181(10):1240-7. doi: 10.7205/MILMED-D-15-00585.

16. Youssef NA, Green KT, Dedert EA, Hertzberg JS, Calhoun PS, Dennis MF, et al. Exploration of the influence of childhood trauma, combat exposure, and the resilience construct on depression and suicidal ideation among US Iraq/Afghanistan era military personnel and veterans. Arch Suicide Res. 2013;17(2):106-22. doi: 10.1080/13811118.2013.776445.

17. Ghaffarzadegan N, Ebrahimvandi A, Jalali MS. A Dynamic Model of Post-Traumatic Stress Disorder for Military Personnel and Veterans. PloS One. 2016;11(10). e0161405. doi: 10.1371/journal.pone.0161405.

18. Yehuda R, Vermetten E, McFarlane AC, Lehrner A. PTSD in the military: special considerations for understanding prevalence, pathophysiology and treatment following deployment. Eur J Pharmacol. 2014;5(1). doi: 10.3402/ejpt.v5.25322.

19. Lee JE, Sudom KA, Zamorski MA. Longitudinal analysis of psychological resilience and mental health in Canadian military personnel returning from overseas deployment. J Occup Health Psychol. 2013;18(3):327-37. doi: 10.1037/a0033059.

20. Green KT, Beckham JC, Youssef N, Elbogen EB. Alcohol misuse and psychological resilience among US Iraq and Afghanistan era veterans. Addict Behav. 2014;39(2):406-13. doi: 10.1016/j.addbeh.2013.08.024.

21. Shatté A, Perlman A, Smith B, Lynch WD. The Positive Effect of Resilience on Stress and Business Outcomes in Difficult Work Environments. J Occup Environ Med. 2017;59(2):135-40. doi: 10.1097/JOM.0000000000000914. [PubMed: 28002352]. [PubMed Central: PMC5287440]. 
22. Rees CS, Breen LJ, Cusack L, Hegney D. Understanding individual resilience in the workplace: the international collaboration of workforce resilience model. Front Psychol. 2015;6(4):73. doi: 10.3389/fpsyg.2015.00073.

23. Duckworth AL, Steen TA, Seligman ME. Positive Psychology In Clinical Practice. Annu Rev Clin Psychol. 2005;1:629-51. doi: 10.1146/annurev.clinpsy.1.102803.144154.

24. Seligman ME, Csikszentmihalyi M. Positive psychology: An introduction. Am Psychol. 2000;55(1):5-14. doi: 10.1037/0003-066x.55.1.5.

25. Sin NL, Lyubomirsky S. Enhancing well-being and alleviating depressive symptoms with positive psychology interventions: a practice-friendly meta-analysis. J Clin Psychol. 2009;65(5):467-87. doi: 10.1002/jclp.20593.

26. Martin E. P. Seligman, Tayyab Rashid, Acacia C. Parks. Positive Psychotherapy. Am Psychol. 2006;61(8):774-88. doi: 10.1037/0003066X.61.8.774.

27. Peterson C, Seligman ME. Character Strengths and Virtues: A Handbook and Classification. New York: Oxford University Press, Inc; 2004.

28. Kristin Layous, Joseph Chancellor, Sonja Lyubomirsky, Lihong Wang, P. Murali Doraiswamy. Delivering Happiness: Translating Positive Psychology Intervention Research for Treating Major and Minor Depressive Disorders. J Altern Complement Med. 2011;17(8):675-83. doi: 10.1089/acm.2011.0139.

29. Martínez-Martí ML, Ruch W. Character strengths predict resilience over and above positive affect, self-efficacy, optimism, social support, self-esteem, and life satisfaction.JPositive Psychol. 2017;12(2):110-9. doi: 10.1080/17439760.2016.1163403.

30. Tugade MM, Fredrickson BL, Feldman Barrett L. Psychological resilience and positive emotional granularity: Examining the benefits of positive emotions on coping and health. J Pers. 2004;72(6):1161-90. doi: 10.1111/j.1467.2004.00294.x.

31. Cousins R, Mackay CJ, Clarke SD, Kelly C, Kelly PJ, McCaig RH. 'Management standards' work-related stress in the UK: Practical development. Work Stress. 2004;18(2):113-36. doi: 10.1080/02678370410001734322.

32. Azad Marzabadi E, Gholami Fesharaki M. [Reliability and Validity Assessment for the HSE Job Stress Questionnaire].JBehav Sci.2011;4(4):1112. Persian.

33. MacKay CJ, Cousins R, Kelly PJ, Lee S, McCAIG RH. 'Manage- ment Standards' and work-related stress in the UK: Policy background and science. Work Stress. 2004;18(2):91-112. doi: 10.1080/02678370410001734322.

34. Kerr R, McHugh M, McCrory M. HSE Management Standards and stress-related work outcomes. Occup Med. 2009;59(8):574-9.

35. Connor KM, Davidson JR. Development of a new resilience scale: The Connor-Davidson resilience scale (CD-RISC). Depress Anxiety 2003;18(2):76-82. doi: 10.1002/da.10113.

36. Khoshouei MS. Psychometric evaluation of the Connor-Davidson resilience scale (CD-RISC) using Iranian students. Int JTest. 2009;9(1):606. doi: 10.1080/15305050902733471.

37. Kamali Z, Fahim M. The Relationship between Critical Thinking Ability of Iranian EFL Learners and Their Resilience Level Facing Unfamiliar Vocabulary Items in Reading. J Lang Teach Res. 2011;2(1). doi: 10.4304/jltr.2.1.104-111.

38. Namdari K, Molavi H, Malekpour M, Kalantari M. [The Effect of Cognitive Hope Enhancing Training on Character Strengths of Disthymic Clients].J Clin Psychol. 2009;1(3):21-34. Persian.

39. Watson D, Clark LA, Tellegen A. Development and validation of brief measures of positive and negative affect: the PANAS scales.J Pers Soc Psychol.1988;54(6):1063. doi: 10.1037/0022-3514.54.6.1063.

40. Khodarahimi S. Hope and flourishing in an Iranian adults sample: Their contributions to the positive and negative emotions. Applied Res Quality Life. 2013;8(3):361-72. doi: 10.1007/s11482-012-9192-8.

41. Masten AS, Powell JL, Luthar SS. A resilience framework for research, policy, and practice. Resilience and vulnerability: Adaptation in the context of childhood adversities. 2003;1:25. doi: 10.1017/CBO9780511615788.003.

42. Luthar SS, Cicchetti D. The construct of resilience: Implications for interventions and social policies. Dev Psychopathol.2000;12(4):857-85. [PubMed Central: PMC1903337].

43. Leimon A, McMahon G. Positive psychology for dummies. John Wiley \& Sons; 2011

44. Matthews MD, Eid J, Kelly D, Bailey JK, Peterson C. Character Strengths and Virtues of Developing Military Leaders: An International Comparison. Mil Psychol. 2006;18(sup1):S57-68. doi: 10.1207/s15327876mp1803s_5. 